\title{
A CUTTING- PLANE APPROACH FOR SEMI- INFINITE MATHEMATICAL PROGRAMMING
}

\author{
M.K Luhandjula (*) and M Ouanes (\&) \\ (*) Université Nationale du Rwanda, Faculté des Sciences et Technologie; \\ B.P.117 Butare.E-mail: jpluhandjula@hotmail.com \\ (\&) Université de Tizi-Ouzou ; Institut des Sciences exactes ; \\ Tizi-Ouzou 15000 ; Algeria
}

\begin{abstract}
Many situations ranging from industrial to social via economic and environmental problems may be cast into a Semi-infinite mathematical program. In this paper, the cutting-plane approach which lends itself better for standard non-linear programs is exploited with good reasons for grappling with linear, convex and geometric Semi-infinite programs. For each case, computational aspects are discussed and convergence statements established. Simple numerical examples are also provided for the sake of illustration. The paper ends by briefly comparing the cutting-plane approach discussed here with other existing approaches and by stressing the necessity of pushing forward a Decision Support System effectively capable for helping someone faced with a problem that can be formulated as a Semi-infinite mathematical program.
\end{abstract}

Keywords: Semi-infinite, Optimization, Cutting-plane, Mathematical program.

\section{INTRODUCTION}

Optimisation theory is one of the most important field of Applied Mathematics. First works on Optimisation theory traced back to 1696.

Since then works on this field include results of foremost mathematicians of the 300 last years: Bliss, Bernoulli, Bolza, Caratheodory, Euler, Fermat, Hamilton, Hilbert, Jacobi, Lagrange, Newton, Weierstrass to mention but a few.

At the moment, the subject has come to maturity and it constitutes the stumbling block for what is done in Operational Research, Decision Theory and Management Science.

The basic Optimisation model consists of minimising or maximising a given functional under some restrictions in the form of mathematical (in)equalities

Extensions that have been made to this basic model include: Incorporation of several stages in an optimisation framework: (Dynamic programming / $1 /$ ). Simultaneous consideration of several conflictual objective functions (Multiobjective programming / $2 /$, / $3 /$ ). Integration of imprecision in an optimisation framework:

( Mathematical programming under uncertainty / 4/, / 5 /, /18/, /19/, /20/).
Consideration of infinitely many constraints (Semi-infinite programming /13/,/14/,/16/, /17/, the subject matter of this paper).

Problems of finding an optimal solution of a mathematical program with infinitely many constraints arise when handling many concrete problems. Let us mention, without any claim for exhaustivity, industrial engineering problems which many be put into a mathematical programming framework while depending on a parameter ranging over a continuum / 8/, Tchebycheff approximation problems $/ 7 /$, max-min problems arising in Game theory.

The «primum movens » of this paper is to add to the spectrum of existing techniques for solving Semi-infinite mathematical programs [7], [8], [9], an approach based on the cutting-plane philosophy [12].

Apart from methodological aspects, convergence results are also established. Simple numerical examples are included for the sake of illustration. The paper is organized as follows: the following section is devoted to the linear case. Section 3 deals with convex semi-infinite programming while in section 4 we give some hints for dealing with the geometric case. The paper ends with concluding remarks along with a comparison of the cutting-plane philosophy with other existing approaches and a claim for implementing Decision Support System for this problem. 


\section{A CUTTING PLANE METHODFORSOLVINGA LINEARSEMI-INFINITEPROGRAM}

\subsection{Problem formulation}

The problem under scrutiny in this section is the linear program:

$$
\left(P_{L}\right)\left\{\begin{array}{l}
\min c x \\
\sum_{r=1}^{n} a_{r}^{i}(s) x_{r} \geq b_{i}(s) \quad ; \quad i=1, \ldots, p ; s \in S ;|S|=\infty \\
x_{r} \geq 0 ; r=1, \ldots, n
\end{array}\right.
$$

Where cî IR ${ }^{\mathrm{n}} ; \mathrm{S}$ is a compact of $\operatorname{IR}^{\mathrm{k}}$; and $\mathrm{b}_{\mathrm{i}}(\mathrm{i}=1, \ldots, \mathrm{p})$ are elements of $\mathrm{C}^{2}(\mathrm{~S})$ and çS ê stands for the cardinal of $\mathrm{S}$.
$\mathbf{G}=\left\{x \in I R^{n} \mid \sum_{r=1}^{n} a_{r}^{i}(s) x_{r} \geq b_{i}(s) ; i=1, \ldots, p, s \in S\right\}$

and

$\mathbf{H}=\left\{x \hat{\mathrm{I}} I R^{n} \hat{\mathrm{e}} A x^{3} b ; x^{3} O\right\}$

Where $\mathrm{A}$ and $\mathrm{b}$ are respectively $\mathrm{m} \times \mathrm{n}$ and $\mathrm{m} \times 1$ matrices chosen so that the condition:

$\boldsymbol{G} \mathbf{I} \boldsymbol{H}$ is fulfilled

\subsection{Algorithm for finding a solution of $\left(P_{L}\right)$.}

The procedure describes by the following flowchart yields an optimal solution of $\left(\mathrm{P}_{\mathrm{L}}\right)$.

The following result gives a justification of the stopping

Let now:

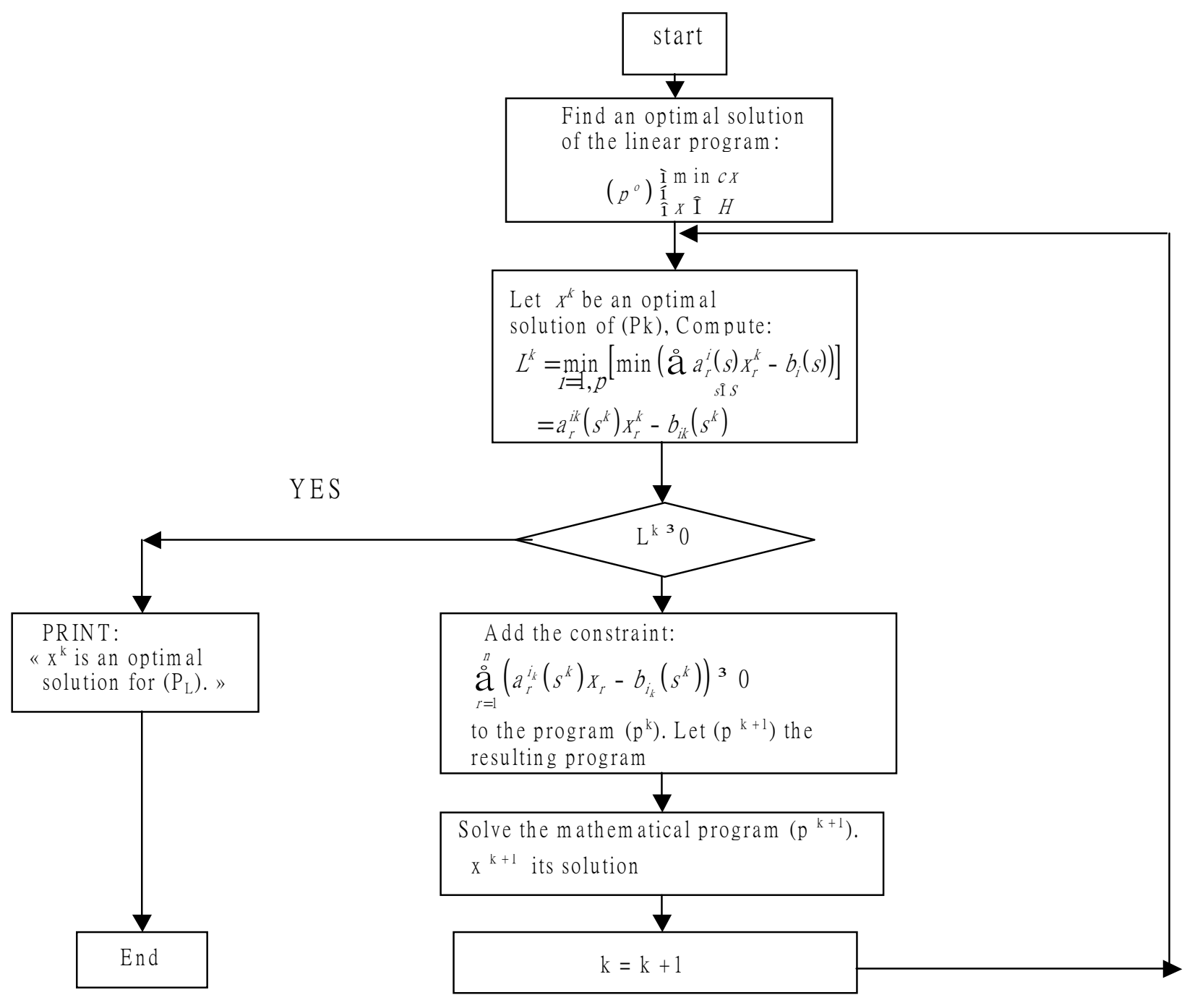

Fig. 1 : Flowchart for solving $\left(\mathrm{P}_{\mathrm{L}}\right)$ 
rule used in the above procedure.

\section{Theorem 2.1.}

Let $\mathrm{x}^{\mathrm{k}}$ be an optimal solution of $\left(\mathrm{P}^{\mathrm{k}}\right)$ and assume that:

1. $L^{k}=\min _{i=1, p}\left[\min \left(\sum_{r=1}^{n} a_{r}^{i}(s) x_{r}^{k}-b_{i}(s)\right)\right] \geq 0$ then $\mathrm{x}^{\mathrm{k}}$ is an optimal solution for $\left(\mathrm{P}_{\mathrm{L}}\right)$

Proof:

- Feasibility

$L^{k} \geq 0 \Rightarrow \min _{s \in S}\left(\sum a_{r}^{i}(s) x_{r}^{k}-b_{i}(s)\right) \geq 0 \quad \forall i=1, \ldots, p$.

This implies that:

$\sum_{r=1}^{n}\left(a_{r}^{i}(s) x_{r}^{k}-b_{i}(s)\right) \geq 0 \quad \forall s \in S ; \quad \forall_{i}=1, \ldots, p$.

i.e. $x^{k}$ is feasible for $\left(\mathrm{P}_{\mathrm{L}}\right)$.

- Optimality.

Let $\mathrm{V}\left(\mathrm{P}_{\mathrm{L}}\right)$ and $\mathrm{V}\left(\mathrm{P}^{\mathrm{k}}\right)$ denotes the optimal values of objective functions

$\left(\mathrm{P}_{\mathrm{L}}\right)$ and $\left(\mathrm{P}^{\mathrm{k}}\right)$ respectively.

We have that:

$\mathrm{V}\left(\mathrm{P}_{\mathrm{L}}\right) £ C \mathrm{X}^{\mathrm{k}}=\mathrm{V}\left(\mathrm{P}^{\mathrm{k}}\right)$

because $\mathrm{x}^{\mathrm{k}}$ is a feasible solution for $\left(\mathrm{P}_{\mathrm{L}}\right)$

Furthermore, we have that the feasible set of $\left(\mathrm{P}_{\mathrm{L}}\right)$ is a proper subset of the feasible set of $\mathrm{P}^{\mathrm{k}}$; so:

$\mathrm{V}\left(\mathrm{P}^{\mathrm{k}}\right)=\mathrm{C} \mathrm{x}^{\mathrm{k}} £ \mathrm{~V}\left(\mathrm{P}_{\mathrm{L}}\right)$

Putting together (1), (2) and (3) we may conclude that $\mathrm{X}^{\mathrm{k}}$ is an optimal solution for $\left(\mathrm{P}_{\mathrm{L}}\right)$.

The question that comes now to mind is what if $\mathrm{L}^{\mathrm{k}}$ fails to become positive or null after a finitely large number of steps. The following result which gives an asymptotic behaviour of the above described procedure, address this question.

\section{Theorem 2.2.}

Any cluster point of the sequence $\left(\mathrm{x}^{\mathrm{k}}{ }_{\mathrm{k}}\right.$ generated by the above described procedure is an optimal solution of $\left(\mathrm{P}_{\mathrm{L}}\right)$.

\section{Proof:}

The existence of a cluster point for $\left(\mathrm{x}^{\mathrm{k}}\right)_{\mathrm{k}}$ is guaranteed by Bolzano-Weierstrass Theorem.

Now let $x^{*}$ be a cluster point of $\left(x^{k}\right)_{k}$. We can find a subsequence $\left(\mathrm{x}^{\mathrm{kj}}\right)$, of $\left(\mathrm{x}^{\mathrm{k}}\right)$ converging to $\mathrm{x} *$. Suppose that $\mathrm{x} *$ is not feasible for $\left(\mathrm{P}_{\mathrm{L}}\right)$, then there is $\mathrm{s} * \hat{\mathrm{I}} \mathrm{S}$ and $\mathrm{i}_{*} \hat{\mathrm{I}}\{1$,

$\ldots ., \mathrm{m}\}$ such that $\sum_{r=1}^{n} a_{r}^{i_{*}}\left(s^{*}\right) x_{r}^{*}<b_{i^{*}}\left(s^{*}\right)$

We can then find $\mathrm{N}$ I IN such that for $\mathrm{k}_{\mathrm{j}}>\mathrm{N}$ we have:

$\sum_{r=1}^{n} a_{r}^{i_{*}}\left(s^{*}\right) x_{r}^{k j}<b_{i^{*}}\left(s^{*}\right)$

Otherwise by taking limit we would have a contradiction to $(*)$

We have also that:

$L^{k j}=\sum_{r=1}^{n} a_{r}^{i_{k j}}\left(s^{k j}\right) x_{r}^{k j}-b_{i_{k j}}\left(s^{k j}\right)$

$=\min _{i=1, p}\left[\min _{s \in S}\left(\sum a_{r}^{i}(s) x_{r}^{k j}-b_{i}(s)\right)\right] \leq \sum_{r=1}^{n} a_{r}^{i}(s) x_{r}^{k j}-b_{r}-(s) \prec 0$

This implies that we may find $\alpha \succ 0$ such that

$b_{i_{k j}}\left(s^{k j}\right)-\sum_{r=1}^{n} a_{r}^{i_{k j}}\left(s^{k j}\right) x_{r}^{k j} \geq \alpha \succ 0$

Furthermore, as is a feasible solution for $\left(P^{k j}\right)$ we have:

$-b_{i_{k j}}\left(s^{k j}\right)+\sum_{r=1}^{n} a_{r}^{i_{k j}}\left(s^{k j}\right) x_{r}^{k j+1} \geq 0$

Adding (4) and (5) yield:

$\sum_{r=1}^{n} a_{r}^{i_{k j}}\left(s^{k j}\right)\left(x_{r}^{k j+1}-x_{r}^{k j}\right) \geq \alpha \succ 0$

Put now:

$\left|x_{r}^{k j+1}-x_{r}^{k j}\right|=\max _{r}\left|x_{r}^{k j+1}-x_{r}^{k j}\right|$

and

$K=\max _{r \in S}\left|a_{r}^{i_{k j}}(s)\right|$ 
We have from (6) that

$n K\left|x_{r}^{k j+1}-x_{r}^{k j}\right| \geq \sum a_{r}^{i_{k j}}\left(s^{k j}\right)\left(x_{r}^{k j+1}-x_{r}^{k j}\right) \geq \alpha \succ 0$

i.e $\left|x_{r}^{k j+1}-x_{r}^{k}\right| \geq \frac{\alpha}{n K} \quad ; \quad$ for $k j \succ N$

This contradicts the fact that $\left(x^{k j}\right)_{j}$ is a Cauchy sequence and $\mathrm{x}^{*}$ should be a feasible solution for $\left(\mathrm{P}_{\mathrm{L}}\right)$. To show that $\mathrm{x}^{*}$ is also optimal we may proceed as in the proof of Theorem 2-1.

\subsection{Numerical example}

Consider the following simple Semi-infinite program for the sake of illustration.

$\left(P_{E}\right)\left\{\begin{array}{l}\min 2 x+1 \\ x+s \geq 1 \quad s \in[0,1] \\ x \geq 0\end{array}\right.$

Applying the method described in \& 2.1, we have by taking: $H=\{x / x \geq 1 / 2, x \geq 0\}$

$\left(P_{E}^{0}\right)\left\{\begin{array}{l}\min 2 x+1 \\ x \geq \frac{1}{2} \\ x \geq 0\end{array}\right.$

and then $x^{0}=\frac{1}{2}$

As $\quad L^{0}=\min _{s \in[0,1]}\left(s-\frac{1}{2}\right)=-\frac{1}{2} \prec 0$ and $x^{0}$ is not an optimal solution for $\left(\mathrm{P}_{\mathrm{E}}\right)$

Consider now the program:

$\left(P_{E}^{1}\right)\left\{\begin{array}{l}\min 2 x+1 \\ x \geq \frac{1}{2} \\ x+0 \geq 1 \\ x \geq 0\end{array}\right.$

We have that $\mathrm{x}^{1}=1$; and:
$\mathrm{L}^{1}=\min (1+\mathrm{s}-1)=0$

sî $[0,1]$

The optimality criterion is met and then the optimal solution of $\left(\mathrm{P}_{\mathrm{E}}\right)$ is $\mathrm{X}^{*}=1$.

\section{A CUTTING-PLANEMETHODFORSOLVINGA CONVEXSEMI-INFINITEPROGRAM.}

\subsection{Problem formulation.}

In this section we'll ponder the mathematical program:

$\left(\mathrm{P}_{\mathrm{c}}\right)\left\{\begin{array}{l}\min f(x) \\ g_{i}(x, s) \geq b_{i}(s) ; i=1, \ldots, p ; s \in S \geq \mathfrak{R}^{K} ;|S|=\infty \\ x \in I R^{n}\end{array}\right.$

Where $\mathrm{f}$ is a convex function and $\mathrm{g}_{\mathrm{i}}(\mathrm{x}, \mathrm{s}) \mathrm{i}=1, \ldots, \mathrm{p}$ are concave functions with respect to the first argument.

Under these assumptions $\left(\mathrm{P}_{\mathrm{c}}\right)$ is a convex program. It is also assumed that $f, g_{i}, b_{i},(i=1, \ldots, p)$ are twice continuously differentiable.

(Pc) may also be written as:

$\left(P_{C}^{\prime}\right)\left\{\begin{array}{l}\min \lambda \\ \lambda-f(x) \geq 0 \\ g_{i}(x, s) \geq b_{i}(s) ; i=0,1, \ldots, p ; s \in S \subset I R^{k} ;|S|=\infty \\ x \in I R^{n}\end{array}\right.$

This program may be put in the form:

$\left(P_{c}^{\prime \prime}\right)\left\{\begin{array}{l}\min c y \\ g_{i}(y, s) \geq b_{i}(s) ; i=0,1 \ldots, p ; s \in S \subset I R^{k} ;|S|=\infty \\ y \in I R^{n+1}\end{array}\right.$

Where: $c=(1,0, \ldots, 0) \hat{\mathrm{I}} \hat{\mathrm{A}}{ }^{n+1}$

$$
\begin{aligned}
& y=\left(\lambda, x_{1}, \ldots, x_{n}\right) \\
& g_{0}(y, s)=\lambda-f(x) \\
& b_{0}(s)=0 \\
& g_{i}(y, s)=g_{i}(x, s) ; i>0
\end{aligned}
$$

Let $K=\max _{i} \max _{y, s}\left\|\nabla g_{i}(y, s)\right\|$ and $H=\left\{y \in I R^{n+1} \mid A y \geq b\right\}$ $\mathrm{A}$ is a $(p+1) x n+1)$ matrix and $b \hat{\mathrm{I}} I R^{p+1}$

$\mathrm{H}$ is defined so that the following condition is met:

$G=\left\{y \in \mathfrak{R}^{n+1} \mid g_{i}(y, s) \geq b_{i}(s) ; i=0,1, \ldots, p ; s \in S\right\} \subset H$ 


\subsection{Algorithm for finding a solution of $\left(P_{C}^{\prime \prime}\right)$}

The following procedure (fig.2) provides a solution for $\left(P_{C}^{\prime \prime}\right)$

A justification of the stopping rule for the above procedure is given by the following:

\section{Theorem 3.1.}

If an optimal solution $\mathrm{y}^{\mathrm{k}}$ of $\left(P_{c}^{k}\right)$ "is such that:

$L_{c}^{k}=\min _{i=0,1, \ldots, p}\left[\min _{s \in S}\left(g_{i}\left(y^{k}, s\right)-b_{i}(s)\right)\right] \geq 0 \_$then $\mathrm{y}^{\mathrm{k}}$ is an optimal solution of $\left(P_{c}^{\prime \prime}\right)$

start

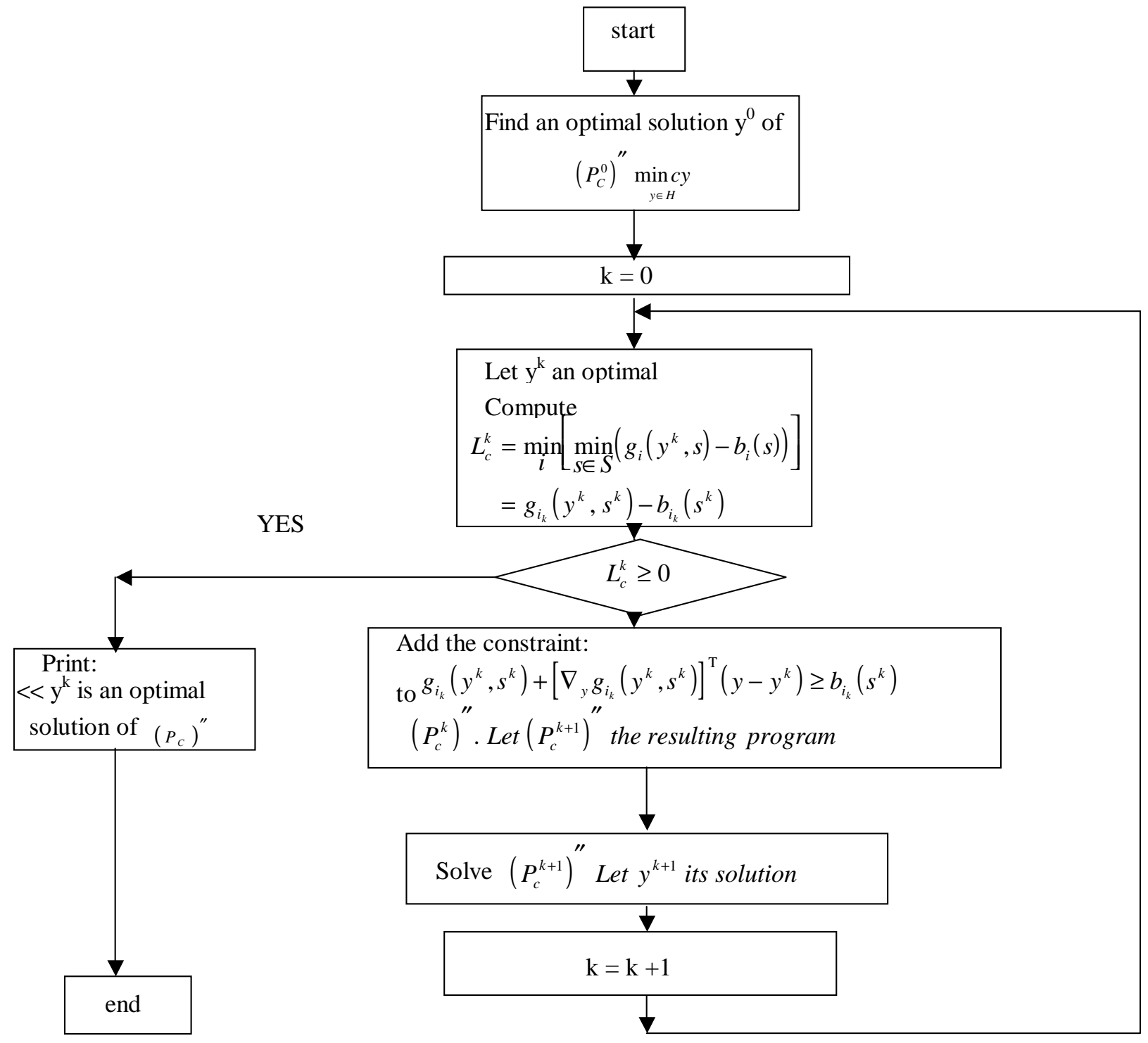

Fig. 2: flowchart of a procedure for solving $\left(P_{c}^{\prime \prime}\right)$. 
The proof of this result is similar to that of Theorem 2.1 and is therefore omitted.

\subsection{Convergence statement.}

In what follows, we assume that the sequence $\left(\mathrm{y}^{\mathrm{k}}\right)_{\mathrm{k}}$ generated by the procedure described in section 3.2 is an infinite one.

\section{Theorem 3.2}

Any cluster point $\mathrm{y}^{*}$ of the sequence $\left(\mathrm{y}^{\mathrm{k}}\right)_{\mathrm{k}}$ is an optimal solution of $\left(P_{c}^{\prime \prime}\right)$.

\section{Proof:}

The existence of a cluster point of $\left(\mathrm{y}^{\mathrm{k}}\right)_{\mathrm{k}}$ is well guaranteed by the Bolzano-Weierstrass Theorem.

Now let $y^{*}$ be a cluster point of $\left(y^{k}\right)_{k}$. Let us show first that $\mathrm{y}^{*}$ is a feasible solution of $\left(P_{c}^{\prime \prime}\right)$.

Let $\left(y^{k j}\right)_{j}$ be a subsequence of $\left(y^{k}\right)_{k}$ converging to $\mathrm{y}^{*}$. Assume now that $\mathrm{y}^{*}$ is not a feasible solution for $\left(P_{C}^{\prime \prime}\right)$. Then there are $s * \hat{I} S$ and $i * \hat{I}\{0,1, \ldots, p\}$

such that: $g_{i^{*}}\left(y^{*}, s^{*}\right) \prec b_{i^{*}}\left(s^{*}\right)$.

Furthermore by the continuity $\mathrm{g}_{\mathrm{i}^{*}}$, there is $N \in I N$ such that for $k j>N$ we have $g_{i^{*}}\left(y^{k j}, s *\right) \prec b_{i^{*}}\left(s^{*}\right)$

We have also that:

$L_{c}^{k j}=g_{i_{k j}}\left(y^{k j}, s^{k j}\right)-b_{i_{k j}}\left(s^{k j}\right) \leq g_{g^{*}}\left(y^{k j}, s^{*}\right)-b_{i^{*}}\left(s^{*}\right) \prec 0$.

This implies using the archimedian property of Â that there is $\alpha \succ 0$ such that:

$b_{i_{k j}}\left(s^{k j}\right)-g_{i_{k j}}\left(y^{k j}, s^{k j}\right) \geq \alpha \succ 0$

But we have also by the fact that $y^{k j+1}$ is a feasible solution of $\left(P_{c}^{k j+1}\right)^{\prime \prime}$ that:

$g_{i_{k_{j}}}\left(y^{k j}, s^{k j}\right)-b_{i_{k j}}\left(s^{k j}\right)+\nabla_{y} g_{i_{k j}}\left(y^{k j}, s^{k j}\right)\left(y^{k^{+1}}-y^{k j}\right) \geq 0$

Adding (6) and (7) yields:

$$
\nabla_{y} g_{i_{k j}}\left(y^{k j}\right)\left(y^{k j+1}-y^{k j}\right) \geq \alpha \succ 0
$$

$$
\begin{aligned}
& 0 \prec \alpha \leq \nabla_{y} g_{i_{k j}}\left(y^{k j}, s^{k j}\right)\left(y^{k j+1}-y^{k j}\right) \\
& \leq\left\|\nabla_{y} g_{i_{k j}}\left(y^{k j}, s^{k j}\right)\right\| \cdot\left\|y^{k j+1}-y^{k j}\right\| \\
& =M\left\|y^{k j+1}-y^{k j}\right\|
\end{aligned}
$$

Where $M=\left\|\nabla_{y} g_{i_{k j}}\left(y^{k j}, s^{k j}\right)\right\|$

Finally we have:

$$
\left\|y^{k j+1}-y^{k j}\right\| \geq \frac{\alpha}{M} \succ 0 \quad \text { for } \quad k j \succ N .
$$

This contradicts the fact that $\left(y^{k j}\right)_{k}$ is a Cauchy in the complete space $\mathfrak{R}^{n-1}$.

So what we have supposed is not true and we have then established the feasibility $\mathrm{y}^{*}$ for $\left(P_{c}^{\prime \prime}\right)$

Let us now show that $\mathrm{y}^{*}$ is an optimal solution for $\left(P_{C}^{\prime \prime}\right)$, we have $V\left(P_{c}^{\prime \prime}\right) \leq C y^{*}$

where $V\left(P_{c}^{\prime \prime}\right)$ denotes the optimal value of $\left(P_{C}^{\prime \prime}\right)$.

Furthermore, we have that the $D\left(P_{C}^{\prime \prime}\right) \subset D\left(P_{c}^{k}\right)^{\prime \prime}$ by construction.

Where $D(P)$ denotes the feasible set domain of the program $(P)$.

Hence $V\left(P_{c}^{\prime \prime}\right) \geq V\left(P^{*}\right)=C y^{*}$

Putting (8) and (9) together, we have:

$$
V\left(P_{c}^{\prime \prime}\right)=C y^{*}
$$

and then $\mathrm{y}^{*}$ is an optimal solution of $\left(P_{C}^{\prime \prime}\right)$.

\subsection{Numerical example}

Consider the mathematical program:

$\left(P_{c}\right)\left\{\begin{array}{l}\min 1-x \\ x^{2}-1 \leq s^{2}+s, s \in[0,1] \\ x \geq 0\end{array}\right.$

Let $H=\{x / x \leq 2\}$; we have that

$H \supset G=\left\{x / x^{2}-1 \leq s^{2}+s ; s \in[0,1]\right\}$

This implies that: 
$\left(P_{c}^{0}\right)\left\{\begin{array}{l}\min 1-x \\ x \leq 2 \\ x \geq 0\end{array}\right.$

We have: $x^{0}=2 ; V\left(P_{c}^{0}\right)=-1$

$$
L_{c}^{0}=-3 \prec 0
$$

and then $x^{0}$ is not an optimal solution of $\left(P_{c}\right)$.

Construct now $\left(P_{c}^{1}\right)$

$\left(P_{c}^{1}\right)\left\{\begin{array}{l}x \leq 2 \\ 4 x \leq 5 \\ x \geq 0\end{array}\right.$

We have: $x^{1}=\frac{5}{4} ; V\left(P_{c}^{1}\right)=-\frac{1}{4}$

$L_{c}^{1}=-\frac{1}{4} \prec 0$ and $x^{l}$ is not an optimal solution of $\left(P_{c}\right)$.

Construct now $\left(P_{c}^{2}\right)$ :

$$
\left(P_{c}^{2}\right)\left\{\begin{array}{l}
\min 1-x \\
x \leq 2 \\
x \leq \frac{5}{4} \\
x \leq \frac{41}{40} \\
x \geq 0
\end{array}\right.
$$

We have the:

$$
\begin{aligned}
& x^{2}=\frac{41}{40} ; V\left(P_{c}^{2}\right)=-\frac{1}{40} \\
& L_{c}^{2}=-\frac{1}{40} \prec 0
\end{aligned}
$$

and then $x^{2}$ is not an optimal solution of $\left(P_{c}\right)$

Construct now $\left(P_{c}^{3}\right)$ :

$$
\left(P_{c}^{3}\right)\left\{\begin{array}{l}
\min 1-x \\
x \leq 2 \\
x \leq \frac{5}{4} \\
x \leq \frac{41}{40} \\
x \leq \frac{20}{41}\left[1+\frac{(41)}{40}\right]^{2} \\
x \leq 0
\end{array}\right.
$$

We have then $x^{3}=1 ; V\left(P_{c}^{3}\right)=0$

and $L_{c}^{3}=0$.

As $L_{c}^{3} \leq 0$; the optimum is reached and is: $x^{*}=1$.

\section{The Geometric case.}

Consider the mathematical program:

$$
\left(P_{G}\right)\left\{\begin{array}{l}
\min \sum_{i=1}^{m} C_{i_{0}} \prod_{j=1}^{n}\left(x_{j}\right)^{\alpha_{i o j}} \\
\sum_{i=m+1}^{n o} C_{i_{l}}\left[\prod_{j=1}^{n}\left(x_{j}\right)^{\alpha_{i j j}} s^{b i l}\right] \leq 1 ; l=1, \ldots P \\
x_{j} \succ 0 ; j=\ldots n \\
C_{i l} \succ 0 ; i=1, \ldots, n_{0} ; l=0,1, \ldots p \\
\alpha_{i_{l}} j \in \Re ; b_{i_{l}} \in \Re, s \in[\alpha, \beta]
\end{array}\right.
$$

Using the transformation:

$x_{j}=e^{y j}$

$\left(P_{G}\right)$ may be put in the form: 
$\left(P_{G}^{\prime}\right)\left\{\begin{array}{l}\min \sum_{i=1}^{m} c_{i o}\left(e^{\sum_{j=1}^{n} \alpha_{i 0 j} y_{j}}\right) \\ \sum_{i=m+1}^{n o} c_{i l}\left(e^{\sum_{j=1}^{n} \alpha_{i j} y_{j}}\right) s^{b i l} \leq 1 ; l=1, \ldots, p \\ y_{j} \in \Re ; b_{i} \in \Re ; s \in[\alpha, \beta]\end{array}\right.$

Let being a continuous one-to-one and monotonic function $\left(P_{G}{ }_{G}\right)$ is equivalent to the program:

$$
\left(P_{G}^{\prime \prime}\right)\left\{\begin{array}{l}
\min \log \sum_{i=1}^{m} c_{i_{0}} e^{\sum_{j=1}^{n} \alpha_{i j} y_{j_{j}}} \\
\log \left[\sum _ { i = m + 1 } ^ { n _ { 0 } } \left[c_{i l}\left[e^{\sum_{j=1}^{n} \alpha_{i j} y_{j}}\right] s^{b_{i l}} \leq 0 \quad l=1, \ldots, p\right.\right. \\
y_{j} \in \Re j=1, n ; c_{i_{l}} \succ 0 ; i=1, \ldots n_{0} ; l=0,1, \ldots, p . \\
\alpha_{i_{j}} \in \Re ; b_{i} \in \Re ; s \in[\alpha, \beta]
\end{array}\right.
$$

\section{Proposition 4.1.}

$\left(P{ }_{G}\right)$ is a convex program

Proof: We have just to show that functions involving in $\left(P{ }_{G}\right)$ are convex.

In other terms, we have to establish the convexity of:

$f_{1}(y)=\log \sum_{i=1}^{m} c_{i} e^{\sum_{j=1}^{n} \alpha_{i j} y_{j}}$

and

$$
f_{2}(y)=\log \sum_{i=m+1}^{n_{0}} c_{i}\left(e^{\sum \alpha_{i j y_{j}}}\right) s^{b_{i}}
$$

To show that $f_{l}$ is convex, take $y^{l}$ and $y^{2}$ in $\hat{\mathrm{A}}^{\mathrm{n}}$ and $\lambda \in(0,1)$ we have to prove that:

$$
f\left(\lambda y^{1}+(1-\lambda) y^{2}\right) \leq \lambda f\left(y^{1}\right)+(1-\lambda) f\left(y^{2}\right) .
$$

Let real numbers $p$ and $q$ such that $p>0, q>0$ $\frac{1}{p}=\lambda$ and $\frac{1}{q}=1-\lambda$.

By Hölder inequality we have:

$\sum_{i=1}^{m}\left(c_{i} e^{\sum \alpha_{i j} y_{j}^{1}}\right)^{\frac{1}{p}}\left(c_{i} e^{\sum_{j=1}^{n} \alpha_{i j} y_{j}^{2}}\right)^{\frac{1}{q}}$

$\leq\left(\sum_{i=1}^{m} C_{i} e \sum_{j=1}^{n} \alpha_{i j} y_{j}^{1}\right)^{\frac{1}{p}}\left(\sum_{i=1}^{m} C_{i} e^{\sum_{j=1}^{n} \alpha_{i j} y_{j}^{2}}\right)^{\frac{1}{q}}$

Taking the Log of the two members yields

$$
\begin{aligned}
& \log \sum_{i}\left(C_{i} e^{\sum_{j=1}^{n} \alpha_{i j} y_{j}^{1}}\right)^{\frac{1}{p}}\left(C_{i} e^{\sum_{j=1}^{n} \alpha_{i j} y_{j}^{2}}\right)^{\frac{1}{q}} \\
& =\log \left\{\sum_{i} c_{i} e^{\sum_{j=1}^{n} \alpha_{i j}\left(\frac{y_{j}^{1}}{p}+\frac{y_{j}^{2}}{q}\right)}\right\} \\
& \leq \frac{1}{p} \log \sum_{i}\left(c_{i} e^{\sum_{j=1}^{n} \alpha_{i j} y_{j}^{1}}\right)+\frac{1}{q} \log \sum_{i}\left(c_{i} e^{\sum_{j=1}^{n} \alpha_{i j} y_{j}^{2}}\right)
\end{aligned}
$$

and we have established (10). To show that $\mathrm{f}_{2}(\mathrm{y})$ is convex, we can proceed in a similar way putting: $\mathrm{c}_{\mathrm{i}} \mathrm{b}^{\mathrm{bi}}=\tilde{c}_{i}$.

$\operatorname{As}\left(P_{G}^{\prime \prime}\right)$ is a convex program, the method developed in section 3 applies.

From this discussion we can draw the following procedure for solving a geometric Semi-infinite program.

\section{CONCLUDING REMARKS}

Since accurate representations of real-world situation may result in mathematical models involving infinitely many constraints Semi-infinite optimization is an important issue. In this paper we have discussed application of the cuttingplane philosophy to Semi-infinite mathematical programming.

The underlying principle of cutting plane methods is to approximate the feasible set of the semi-infinite program by finite set closed-half spaces and to solve a sequence of approximating linear programs[1], [6]. 


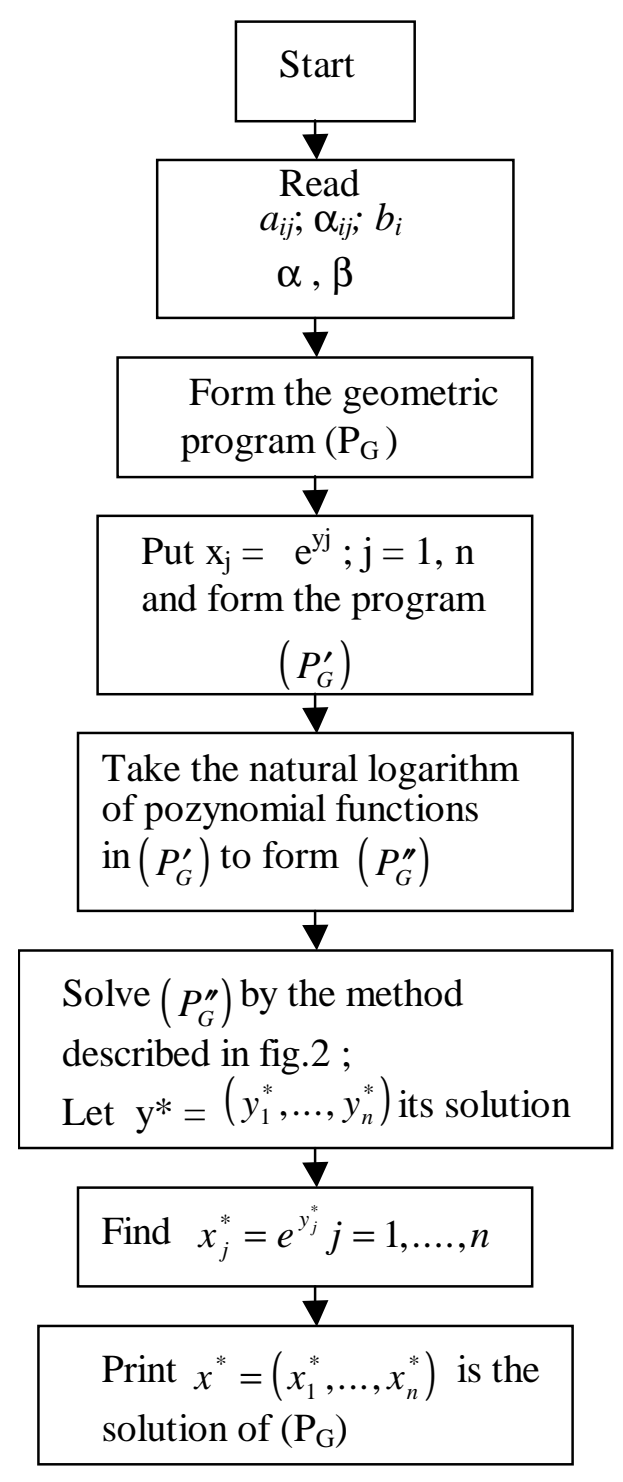

Fig. 3: Flowchart for solving $\left(\mathrm{P}_{\mathrm{G}}\right)$.

Construction of cutting-planes for the linear, the convex and the geometric cases is carried out by finding appropriate supporting hyperplanes to the feasible set.

Under not too restrictive assumptions, it has been shown that either proposed computational schemes generate a solution in a finite number of steps, or it generate an infinite sequence accumulation points of which are optimal solutions of the original Semi-infinite program.

The cutting-plane approach discussed in this paper deliver an exact solution in two ways. Either the termination criterion is met after a finite number of iterations, or if this is not the case, one may find a solution by finding the limit of a convergent subsequence extracted from the sequence generated by the procedure.

This is an advantage over existing discretization approaches /4/, /7/, where only an approximate solution is guaranteed.

Furthermore, the above-mentioned cutting-plane approach allows tackling problems having some non-linearity. This is not possible for the three-phases approach /2/ for instance.

An interesting line for further investigation is to push forward a user-friendly Decision Support System encapsulating discretization methods, three phrases approaches and the cutting-plane scheme discussed here.

Such a Decision Support System may help in effectively helping a Decider faced with problem that may be cast into a Semi-infinite program.

Other lines for further inquiries include taking into account conflicting objective functions into a semi-infinite program and incorporating imprecise data into a Semi-infinite program.

\section{ACKNOWLEDGEMENTS}

The first Author is indebted to the United Nations University for having financially supported him during the realisation of this work. (Contract ICA $n^{\circ}$ 98/052).

\section{REFERENCES:}

Beellman, R.E., Dynamic Programming; Prineton Universty press, 1957.

Hwang C.L., Paidy S.R., Yoon K. and Masud A.S.M., Mathematical programming with multiple objectives: a tutorial; Comput. Opns. Res. 7, 531,1980

Dauer J.P. and Krueger R.J., An iterative approach to goal programming; Opl. Res. Q. 28, 6671-681, 1979.

Kall P., Stochastic Linear Programming (Springer, BerlinNew York) 1976.

Luhandjula M.K.; Fuzzy Optimisation: An appraisal. Fuzzy sets and systems;30, 257-282, 1989.

M. Avriel; Non-linear programming: Analysis and Methods. Prentice-Hall ine Englewood Cliffs N.J. 1976. 
Glashoff-Gustafson; Linear optimisation and approximation; Amplitude Math. Sciences Springer Verlag 1983

Hettich and Van. Honstede; On quadratically convergent method for semi-infinite programming . Bonn University Germany 1979.

M. K. Luhandjula, M. Belhouas, M. Ouanes; Semi-infinite mathematical programming a collocation approach; International Center for Theoretical Physics Trieste Italy 1994

M. K. Luhandjula, H. Inuiguchi, M. Ichihashi; Fuzzy and semi-infinite mathematical programming ; Information Sciences, 61 (1992).

Moktar S. Bazaraa, Hanif D. Sherati, C.M. Shetty Nonlinear programming theory and Algorithms (Second Edition)John Wiley and Sons, Inc. 1993.

M. Ouanes: Sur la programmation semi-infinie, dissertation; Université Tizi-Ouzou 1992.

J.W. Blankeship and J.E.Falk; Infinitely constrained optimizing problem. J.Optimization problem . J.Optim.Theory 19(1976) 261-281.

R.Hettich, Semi-infinite Programming; (Springer, BerlinNew York 1979).

R.Steuer, Algorithms for linear programming problems with interval objective coefficients . Math. Oper. Res.6(1981)333-34

A.L. Soyster; Convex programming with set inclusive constraints; Application to inexact programming. Oper.Res.21(1973)1174-1157.

B.Timsi and D.Kerri; Programmation Semi-infinie: Analyse Réalisation et Applications. Dissertation Université de Tizi-Ouzou(1987).

S.Vajda, Probabilistic programming. Academic Press, New York 1972.

A.V.Yazenin, Fuzzy and Stochastic Programming . Fuzzy sets and Systems 22 (1987) 171-180.

M.K Luhandjula, A.O; Djungu and N.M Kasoro, On Fuzzy Probabilistic Linear Programing . Ann.Fac. Sci. Université de Kinshasa No 3(1977) 45-60. 